\title{
A IMPORTÂNCIA DA COMUNICAÇÃO NA GESTÃO PÚBLICA E SUA INFLUÊNCIA E RELAÇÕES COM OS INTERESSES PÚBLICOS, POLÍTICOS E TRANSPARÊNCIA GOVERNAMENTAL: O CASO DA PREFEITURA DE CASTRO - PARANÁ
}

\author{
THE IMPORTANCE OF COMMUNICATION IN PUBLIC MANAGEMENT \\ AND ITS INFLUENCE AND RELATIONS WITH THE PUBLIC INTERESTS, \\ POLITICIANS AND GOVERNMENT TRANSPARENCY: THE CASE OF THE \\ MUNICIPALITY OF CASTRO - PARANÁ
}

\author{
Edson Gil Santos Júnior*
}

\begin{abstract}
RESUMO
Atualmente a comunicação é uma importante ferramenta de divulgação das ações dos agentes públicos e com ela está a responsabilidade de apresentar informações de utilidade pública que façam a função de prestação de contas. Com a maior acessibilidade das mídias comunicacionais, permitidas pelo crescente avanço tecnológico, a mudança de comportamento do cidadão frente à cobrança dos serviços prestados pelos governos é crescente e, por este motivo, indispensável para a democracia. Através da comunicação na gestão pública, a população pode tomar ciência de ações em várias áreas, por exemplo, o emprego dos recursos públicos, a divulgação de políticas públicas, planejamento estratégico governamental, transparência e responsabilidade fiscal. Este artigo apresenta uma análise descritiva dos recursos midiáticos utilizados e os resultados do trabalho dos profissionais públicos da comunicação da Prefeitura de Castro no Paraná. O recorte temporal aborda as gestões de 2005-2008 e 2009-2012, em que os agentes de comunicação buscaram preparar os gestores, ou seja, os secretários municipais e o próprio prefeito, a fim de utilizarem a imprensa a favor dos interesses públicos e de gestão para cumprirem de forma eficiente o papel de informar a população de maneira inclusiva aos interesses político-econômico-sociais, não se limitando à promoção pessoal dos cargos eletivos.
\end{abstract}

Palavras-chave: Gestão Pública. Comunicação Pública. Transparência. Interesse Público.

\begin{abstract}
Today communication is an important tool for dissemination of the actions of public officials and it is the responsibility of presenting information and utilities
\end{abstract}

\footnotetext{
*Especialista em Gestão Pública pela Universidade Estadual de Ponta Grossa (UEPG) e graduado em Comunicação Social - Jornalismo pela mesma instituição. Email: edsongil_jornalista@hotmail.com
} 
that make the function of accountability. With the increased accessibility of communication media, permitted by the growing technological advancement, the changing behavior of the citizen against the collection of services provided by governments is increasing and therefore, indispensable to democracy. Through communication in public management, population science can take action in several areas, for example, the use of public funds, disclosure of public policy, strategic planning, government transparency and fiscal responsibility. This article presents a descriptive analysis of media resources used and the results of the work of professional public communication Prefectural Castro in Paraná. The time frame covers the administrations of 2005-2008 and 2009-2012 in which agents of communication sought to prepare managers, or else, the municipal mayor himself and to use the press in favor of public interests and management in order to meet efficient, the role of informing the public interests so inclusive political-economicsocial and not limited to the promotion staff of elected office.

Keywords: Public Management. Public Communication. Transparency. Public Interest.

\section{Maior proximidade do governo com a po- pulação}

Como parte integrante da máquina pública, a comunicação cumpre um fundamental e decisivo papel no processo eleitoral, como também na exposição do trabalho efetuado em uma gestão. Desde a redemocratização do país, a comunicação pública passa por uma constante avaliação pelos profissionais dos meios de comunicação, mas principalmente pelos profissionais das assessorias de comunicação governamental.

Divulgar a eficiência de políticas públicas e transparência na utilização de recursos está em constante ascensão na gestão governamental brasileira. Com a intenção eleitoral futura ou pela exigência da Lei de Responsabilidade Fiscal, os órgãos públicos utilizam a comunicação para inserir o cidadão no contexto político-econômico tanto das cidades, como do estado ou mesmo da federação.

No período do regime militar, entre as décadas de 60 a 80, por mais que ocorressem movimentos de redemocratização e contestações contra o modo de governo, grande parte da população ficou por muito tempo alienada à situação do país. Mesmo com a redemocratização do Brasil, o cidadão ainda não participa das decisões políticas a não ser que seja obrigado pelo voto nas eleições.

Pode-se dizer que a internet e a abertura política do país representaram um avanço da importância da comunicação para uma maior participação da população no cenário político e consequentemente governamental. De acordo com Cunha (2005, p.2):

as tecnologias de informação e comunicação, de fato, abriram oportunidades para transformar o relacionamento entre governo, cidadão, sociedade civil organizada e empresas, contribuindo para alcançar a boa governança e, especialmente na dimensão da transparência.

Cunha $(2005$, p.3) cita a conceituação dada pela UNESCO,

Um exemplo bem interessante de transparência é uma aplicação no sítio da Secretaria de Educação do Paraná (http://www.diaadiaeducacao.pr.gov.br/ escolas/frmPesquisaEscolas.jsp, 11/07/2005). O poder público possui informações sobre as escolas, tais como obras realizadas - reforma de telhados, construção de quadras, reforma de prédios, número de salas, merenda escolar que a escola recebe e distribui, material escolar, transferências de recursos para associações de pais e mestres e outras.

Segundo esta conceituação, a governança eletrônica abrange três grandes ramos: a e-administração, e-serviços e a e-democracia. Ela discorre que a e- administração é um suporte digital para a implementação de políticas públicas, como, por exemplo, a obrigatoriedade de publicação dos resultados, baseada na Lei de Responsabilidade Fiscal (LRF) que busca a transparência do uso do dinheiro público.

De acordo com Gerzson e Müller (2009), a sociedade passa por um momento de reavaliação de 
sua participação no próprio envolvimento das ações públicas. É indicado ainda que a contemporaneidade tem exigido reposicionamento desse paradigma referente às relações entre organizações públicas e seus públicos, como citado pelos autores:

A sociedade está exigente no que se refere aos seus direitos - inclusive o de ser bem atendido. Ao mesmo tempo em que surge essa consciência, as práticas de comunicação pública passam por crises de identidade e se percebe a importância da adoção de práticas mais democráticas e direcionas, em oposição ao viés de massificação historicamente adotado pelo setor público. (GERZSON; MÜLLER, 2009, p. 63).

Entretanto, esta mudança ainda caminha a passos lentos. Duarte (2011) cita uma pesquisa realizada pelo Ibope em 2003, para o Observatório da Imprensa, na qual uma das conclusões foi que, enquanto $44 \%$ dos brasileiros gostariam de influenciar nas decisões do país, os outros $56 \%$ não demonstraram nenhum interesse pelos feitos políticos.

Temos, então, um governo que, além de ter que se adaptar aos recursos tecnológicos de informação, é também obrigado a utilizar destes meios para cumprir a lei. Por outro lado, a população, diferente de outrora, busca as informações disponibilizadas de maneira ainda tímida, para entender e participar de decisões, nem que seja, em último caso, por meio do voto, ajudando a não eleger algum representante que se demonstre "indigno" de ocupar um cargo público.

Gomes Filho (2005) salienta que informação gera mais informação; ou seja, a partir do momento em que o gestor publica dados, a sua divulgação, tanto pelos órgãos oficiais como pela mídia, acaba gerando o debate entre a sociedade e fortificando a democracia. Quanto a isto, o autor cita:

Essa emergência da informação, como conseqüência dos processos de informatização, montou o cenário favorável à promoção da transparência. As pessoas naturalmente tendem a avaliar positivamente a transparência no relacionamento humano. Com o avanço dos processos que definem a globalização, aumentou a transparência, na medida em se derrubaram barreiras, se transpuseram fronteiras e se venceram limites que separavam as pessoas, dando margem a um ambiente de valorização da liberdade. E um ambiente de liberdade oferece as condições para que crie uma cultura da informação. E informação gera mais informação. (GOMES FILHO, 2005. p. 5).
Por isso é conveniente distinguirmos os meios de comunicação com a comunicação em si, pois, enquanto a comunicação representa um processo social primário, os chamados meios de comunicação de massa constituem apenas uma mediação tecnológica em relação a esse processo. Ferreira (s/d) discorre que todo processo de comunicação deve ser analisado sob a ótica de três elementos: os públicos, os profissionais da comunicação e as mediações. Assim, é integrado pelas atividades de jornalismo (representado através das assessorias de imprensa, é um elo entre o poder público e os meios de comunicação); relações públicas (formar públicos, levantar as controvérsias, fornecendo todas as informações e facilitando a discussão à procura de opinião ou decisão) e publicidade/propaganda (conjunto de técnicas e atividades de informação e persuasão cujo objetivo é atrair a atenção do público para a marca, a mensagem publicitária para influenciar opiniões e comportamentos). Especificamente, a publicidade é considerada como um dos princípios que devem ser obedecidos pela administração pública. (FERREIRA, s/d, p. 6).

Para melhor compreender esse quadro, diversos autores discorrem sobre a comunicação pública, não como maneira de manejar a massa com informações com cunho de promoção de um grupo político, mas como um caminho para democratizar a informação de forma que o cidadão se sinta mais preparado para interpretar, questionar, discutir e, por que não, participar de decisões políticas por intermédio de associações, ONGs, entidades ligadas ao poder público, partidos políticos e pela escolha no voto de suas decisões. Segundo Duarte (s/d), "a Comunicação Pública ocupa-se da viabilização do direito social coletivo e individual ao diálogo, à informação e à expressão. Assim, fazer comunicação pública é assumir a perspectiva cidadã na comunicação envolvendo temas de interesse coletivo". Para Lopes (2007, p.9),

No lugar de uma relação meramente unidirecional, na qual o governo provê o cidadão com as informações que julga pertinente utilizando apresentação e edição que entende adequadas, a teoria política contemporânea entende que o envolvimento dos cidadãos nas políticas públicas deve ser bidirecional. Tal prática, aliada à melhora da transparência governamental, tende a reduzir de maneira considerável a assimetria de informação e, consequentemente, os abusos cometidos pelas autoridades governamentais. 
Citando Christensen e Laegreid (2002), Lopes acrescenta que o cidadão deve ser mais do que um simples apoiador da democracia por meio do voto, mas que deve ter acesso a todos os mecanismos necessários para agir como membro de algum grupo de interesse, para que possa exercer de fato a tão propalada "cidadania" em um ambiente de efetiva "poliarquia".

Lopes (2007) citando Valente (2004) afirma que, quando se trata da falta de informação em relação aos órgãos públicos, "o silêncio é a arma do poder que omite dados". O autor comenta também que governar não é algo fácil, considerando que o interesse público diverge muitas vezes, por exemplo, entre moradores de uma mesma rua, pois o que pode ser feito para o benefício geral pode agradar a um morador, mas desagradar a outro. Por isto, "governar é avaliar, analisar, debater e optar entre possibilidades quase infinitas de ações que, normalmente trazem benefícios para alguns e malefícios para outros". Mesmo assim, não satisfazendo a todos, cabe ao gestor informar o que está sendo feito para justificar o emprego do dinheiro público.

\section{Comunicação na gestão pública e na gestão operacional}

A comunicação social no âmbito da administração pública pode ser encaixada em diversas áreas correlatas de gestão e com isso está atrelada ao funcionamento da máquina pública. Valores éticos e formadores de conceito da opinião pública permeiam a maneira como é tratada a divulgação das ações dos órgãos e indiretamente dos gestores públicos que têm o interesse próprio condicionado à mesma importância do que julga ser o interesse público, por motivos eleitorais.

$\mathrm{Na}$ gestão operacional, o controle externo presta contas aos tribunais de contas e câmaras municipais, estaduais e federais; ação do mesmo gênero é feita pela mídia, cujo papel é o de levar voluntariamente informações dos órgãos públicos para a população. Como comenta Malmegrin (2010), "a participação da sociedade e o fortalecimento das procuradorias estão viabilizando, mesmo de forma lenta relativamente às expectativas dos cidadãos, o chamado controle social". A autora cita também:
Corroborando com nossa escolha, temos também a relevância do controle quando pensamos em ação do controle estatal que aparece sistematicamente abordada em jornais e em outros veículos de comunicação, com notícias e análises sobre paralisações de obras ou mesmo de contratações de serviços as quais foram identificadas como irregulares por Tribunais de Contas e procuradorias da União, Estados e municípios. (MALMEGRIN, 2010, p.42).

Malmegrin (2010) comenta também que tanto o controle operacional pelos órgãos competentes ainda é vista, em muitos momentos, de maneira negativa, associada a punições ou restrições à administração; por outro lado, a fiscalização da mídia se apresenta como agente regulador e é a maneira de a população se sentir parte deste contexto de controle, pois mesmo não tendo possibilidade de fazer algo para mudar o cenário da administração pública, fica informada do trabalho dos gestores. E quanto às ações de controle, cita o que deve ser feito:

Aproveitar os pontos positivos do controle e minimizar seus impactos, as consequências negativas, é um desafio de todos, do Estado e da sociedade, e em especial do gestor operacional, pois, nesse nível é que as ações de controle são mais efetivamente visíveis aos diversos públicos-alvo. (MALMEGRIN, 2010, p.44).

Pode-se, então, definir o trabalho da comunicação social na gestão operacional como uma ação contínua, pois, ao contrário das ações situacionais ou sazonais, aquele trabalho se caracteriza como intrínseco ao andamento das ações de gestão, dando a visibilidade necessária.

\section{Comunicação e planejamento estratégico}

Para Ruiz (s/d), a comunicação como um todo passa a ser um fator estratégico no cumprimento das ações a serem realizadas pelos funcionários. A divulgação do que é planejado estrategicamente pelo poder público é aceito como um compromisso de que será executado, além de cumprir um papel de projeção do que será efetuado. Em relação à comunicação e o planejamento estratégico, o autor cita:

Assim sendo, dentro do Planejamento Estratégico, os objetivos estratégicos e suas formulações passam a ser compartilhados e a existir real comprometimento das pessoas, gerando não somente 
sentido de pertença, mas um crescimento na auto-estima. O processo comunicacional tem que ser visto como vital para o crescimento, funcionamento e projeção da organização ao futuro. $\mathrm{O}$ desempenho das pessoas é acompanhado, com base em objetivos e padrões consensados e os ajustes necessários de correção de rumo são feitos de forma natural. (RUIZ, s/d, p.1).

Esta credibilidade almejada é um dos principais fatores da valorização da comunicação nas organizações contemporâneas. De acordo com Mendes e Moreira (2008), a comunicação é responsável pelo bem mais valioso da instituição, algo valorizado interna e externamente, a reputação. Na garantia desse fator é necessário que o que for divulgado como planejamento na esfera pública seja devidamente cumprido, como uma assinatura em um cheque. Entretanto, é importante revisar o que é a ação de planejar:

Planejar é conhecer e entender o contexto; é saber o que se quer e como atingir os objetivos; é saber como se prevenir; é calcular os riscos e buscar minimizá-los; é preparar-se taticamente; é ousar as metas propostas e superar-se de maneira contínua e constante. Planejar não é só vislumbrar o futuro, mas é também uma forma de assegurar a sobrevivência e a continuidade dos negócios. (CHIAVENATO; SAPIRO, 2003, apud MENDES; MOREIRA, 2008, p. 9-10).

Ainda, segundo os autores, a estratégia deve ser levada aos componentes da organização de uma forma tangível, para que todos possam conhecê-la e trabalhar em conjunto para sua implementação e garantir que o que foi planejado e divulgado torne-se elemento comprobatório para a população. Tanto para Mendes e Moreira (2008), como para Ruiz (s/d), planejamento estratégico e comunicação devem andar juntos, como é indicado na citação de Mendes e Moreira (2008, p.7):

Da mesma forma, não é mais possível pensar modalidades e produtos de comunicação organizacional como elementos isolados, capazes de gerar resultados independentemente. É preciso integrar as ações de comunicação e as ações estratégicas em geral.

\section{Divulgação de políticas públicas}

De acordo com Demo (2007, p.9, apud ROSA, 2010, p.2), a política pública social em nível administrativo é uma "proposta planejada de enfrentamento das desigualdades sociais". O autor defende que essa prática deve apresentar algumas características específicas, que seja "redistributiva de renda e de poder [...], equalidadora de oportunidades [...], e sempre que possível emancipatória” (DEMO, 2007, p.20-23). Além disso, como indica Duarte (s/d), a Constituição Federal de 1988, em seu artigo 37, garante que o uso da comunicação para os órgãos governamentais "deverá ter caráter educativo, informativo e de orientação social".

Por outro lado, a imprensa pode servir para ações de vigilância, assumindo, se assim o desejar, o papel de servir ao cidadão, monitorando e denunciando ações de irregularidades no poder governamental, como se pode perceber constantemente pela quantidade de denúncias contra a corrupção que ocorrem no âmbito dos três poderes governamentais. Mesmo agindo como agente regulador, crítico e denunciador, a imprensa cumpre um papel de reconhecimento das ações desenvolvidas pelos órgãos governamentais em prol da população, contanto que tenha o reconhecimento do beneficiado, neste caso, o cidadão.

Por isto, a imprensa, além dos dados apresentados nas publicações oficiais elaboradas pelas assessorias de comunicação dos órgãos públicos, utiliza-se de outros dados para comprovar a eficácia de uma ação governamental, como o uso de personagens da população, dos dados estatísticos de índices socioeconômicos e, ainda, das decisões do Poder Judiciário, para avaliar a legalidade da ação em alguns casos.

A função da comunicação governamental vem sendo analisada por vários teóricos, os quais apresentam definições que a valorizam, por exemplo:

a Comunicação Governamental pode ser entendida como Comunicação Pública, na medida que ela é instrumento de construção da agenda pública e direciona seu trabalho para a prestação de contas, o estímulo para o engajamento da população nas políticas adotadas, o reconhecimento das ações promovidas nos campos políticos, econômico e social, em suma provocar o debate político. Trata-se de uma forma legítima de um governo prestar contas e levar ao conhecimento da opinião pública os 
projetos, ações, atividades e políticas que realiza e que são de interesse público. (BRANDÃO, 2006, p. 6).

Por isso, é de suma importância que a interação dos órgãos públicos com a imprensa ocorra tanto para a constante divulgação das ações do governo como também para que seja cumprido o dever do jornalista de, em caso de denúncias ou reclamações dos serviços prestados pelo poder público, ser impreterivelmente ouvido o lado governamental para que justifique o motivo da insatisfação da população.

\section{Comunicação pública na Prefeitura de Castro}

A atual gestão (2008-2012) da cidade de Castro está em seu segundo mandato, o que possibilita fazer a avaliação em um período que abrange os últimos oito anos; entretanto, como recorte temporal para embasar esta pesquisa foram selecionados os anos de 2006, 2009 e 2011 para o levantamento de dados e, assim, avaliar as diferenças.

A metodologia aplicada na pesquisa foi a consulta dos materiais desenvolvidos pela assessoria de comunicação, como mídia training, jornais informativos, cadernetas de bolso, site, releases e acervo fotográfico, como documentos e fontes de pesquisa em uma análise descritiva. De acordo com Lopes (1999), a pesquisa é um estudo descritivo, com ênfase na coleta e sistematização de dados de uso prático empírico, enquanto parte de pesquisa social contribui para o corpo de conhecimentos teóricos e metodológicos de um determinado campo estudos.

El análisis descriptivo envuelve operaciones analíticas de la formación de evidencias empíricas representativas en aquello que se denomina "proceso de reconstrucción de la realidad del objeto". Es hecho a través de métodos descriptivos que son "métodos técnicos" como el estadístico, el etnográfico, el historiográfico, el análisis de contenido, para citar los más usados en las investigaciones de comunicación. De manera complementaria y sucesiva, el análisis interpretativo envuelve operaciones de síntesis que llevan a la formación de las inferencias teóricas y de la explicación del objeto, utilizando métodos lógicos que son métodos de interpretación. (LOPES, 1999, p.10).

Deve ser lembrado que foi instaurada na prefeitura uma equipe no início da primeira gestão para a Superintendência de Comunicação Social, que desenvolveu dois projetos para entrosar o prefeito e os secretários para o contato inevitável com a imprensa. De acordo com Ramos (2005), todas as pessoas que ocupam cargos na administração pública, sejam os cargos eletivos ou os de confiança dos mandatários, têm a obrigação de responder aos meios de comunicação que servem de ponte aos interesses da população, dando-lhe, inclusive, ciência quanto às ações públicas. Cita o autor:

A primeira e fundamental consequência de se reconhecer o direito à comunicação é entender de que ela precisa ser vista como passível de discussão e ação enquanto política pública essencial, tal como políticas públicas para os segmentos de saúde, alimentação, saneamento, trabalho, segurança, entre outros. (RAMOS, 2005, p.6).

O preparo do primeiro escalão da gestão da Prefeitura de Castro ocorreu através da oferta de um mídia training, no qual os funcionários tiveram orientações de como proceder no contato direto com os meios de comunicação e como se relacionar com a imprensa, por exemplo, como se comportar, como se vestir (em caso de aparições televisivas) e o quê e como falar em uma entrevista. Neste treinamento foi indicada a importância da boa convivência com a mídia. O Manual de Assessoria de Comunicação (FENAJ, 2007) comenta que a conquista da credibilidade com o jornalista e consequentemente com os meios de comunicação fará do assessorado uma boa fonte de informação, sempre requisitada. Esta relação, praticamente impossibilitará que uma notícia sobre uma pasta específica da prefeitura seja publicada sem ser ouvida a versão do secretário em questão. Um dos principais fatores destacados é nunca deixar de atender a imprensa, como observado a seguir:

Para as organizações sérias e comprometidas, o instrumento de comunicação é o que permitirá seu reconhecimento perante a sociedade, principalmente neste novo milênio em que o mundo globalizado elevou a informação a um produto de grande valor. (FENAJ, 2007).

Outra estratégia utilizada deu-se pela confecção de uma caderneta de bolso, através da qual os secretários e também o próprio prefeito pudessem consultar sobre determinados assuntos em situações em que não fosse possível o contato com o assessor de imprensa. A caderneta de bolso era composta 
de informações sobre o plano de governo, pacote de obras e realizações da administração.

Entre os meses de fevereiro a julho de 2006, a Superintendência de Comunicação produziu 375 releases e não se tinha uma noção do conteúdo fotográfico de eventos oficiais, obras e outros registros de atividades da prefeitura que merecessem registro oficial. Em 2009, a quantidade de releases produzidos acompanhou a mesma quantidade do período anterior, mantendo uma média de 2,5 releases diários e três mil fotografias arquivadas. No entanto, em 2011, nos meses de fevereiro a junho, a produção alcançou 440 releases e mais de quatro mil fotografias.

Como em qualquer prefeitura, os releases são enviados para todos os jornais, emissoras de rádio e televisão da região dos Campos Gerais e para os principais veículos de comunicação do Paraná. Da mesma maneira é a função dos profissionais da $\mathrm{Su}-$ perintendência de Comunicação Social, atender imediatamente qualquer pedido de informação por parte da imprensa, não interessando a orientação política ou vulto da empresa jornalística solicitante.

Além deste cuidado com o contato com os meios de comunicação, cabe a Superintendência de Comunicação Social da prefeitura, a criação de veículos de divulgação próprios orientados para públicos específicos. A intenção é divulgar as políticas públicas de diferentes áreas da administração para cada público. Para isso, após diversos modelos de informação direcionada, a prefeitura resolveu contar com dois informativos semestrais além do diário oficial, que tem uma periodicidade semanal.

Os informativos são específicos em duas áreas importantes e de bastante visibilidade no que se trata de políticas públicas. As publicações são os jornais de obras e da saúde. Atualmente, o jornal da saúde foi extinto e as notícias desta área fazem parte do jornal Castro em Ação, composto pelas ações realizadas pelas Secretarias de Saúde, Educação, Indústria, Comércio e Turismo, Assistência Social e Esporte e Cultura. Enquanto isso, o jornal de obras continua em destaque, sendo o principal canal de informação das realizações da prefeitura nesse setor, o qual apresenta um grande número de obras próprias ou de convênios, executadas nos últimos anos. Indicando que esta ação de comunicação dirigida é de valor, podemos citar Gerzson e Müller que afirmam:
Mais do que transmitir a mensagem, é primordial estabelecer meios adequados de atingir os públicos de interesse. Nesse sentido, os instrumentos de comunicação dirigida representam competentes aliados das organizações públicas na sua aproximação com o cidadão e na possibilidade de atingir melhores resultados comunicativos. (GERZSON; MÜLLER, 2009, p.64).

Atingir a um público de interesse com informações sobre a administração pública não deve se limitar ao interesse reprovável de promoção do gestor público, objetivando futura valorização em pleitos eleitorais. Quando dito público de interesse, é o interesse do cidadão que está em questão. Recentemente, a Prefeitura de Castro desenvolveu um informativo de obras e ações para a localidade do Abapan em Castro. No local, que conta com cerca de sete mil moradores - número representativo para influenciar no resultado de uma eleição -, foram feitas diversas obras, melhorias estruturais e de atendimento ao cidadão, nada mais justo que fazer um veículo direcionado para esta parcela do município.

Entretanto, fazer comunicação pública nem sempre é uma atividade fácil, pois diversos interesses eleitorais estão envolvidos. Por isso, cabe à equipe de comunicação ficar atenta diante da lei de propaganda eleitoral antecipada.

A propaganda eleitoral consiste na divulgação de ideias e opiniões, visando captar a simpatia do eleitorado e obter-lhe o voto. O objetivo da propaganda eleitoral é angariar votos. Trata-se de espécie de propaganda política, assim como a propaganda intrapartidária e a propaganda partidária. (ROLLO, s/d, p.1).

Fugir do que ensina a lei é bastante comum em cidades pequenas, onde o gestor e seus secretários se utilizam desta prática ilegal para manter o eleitorado fiel, tema que até já tem referências na literatura:

Nas pequenas cidades, em especial, a comunicação se restringe à comunicação política do prefeito e dos secretários, "o conceito de comunicação pública nem sequer passa pela porta da prefeitura". (OLIVEIRA, 2003, p.12).

$\mathrm{Na}$ busca de efetuar um trabalho de assessoria em comunicação responsável, os informativos de ações e de obras da atual Prefeitura de Castro, inclusive o informativo direcionado para a comunidade 
do Abapan, não se utilizou de promoção pessoal do gestor. Nessas publicações foi evitada a utilização do nome do gestor e em suma necessidade foi utilizado o nome do secretário responsável pela pasta abordada. Assim, evidenciou-se que as obras foram feitas para atender às demandas da região, sem caracterizar o intuito de um grupo político em obter vantagens eleitoreiras.

Espera-se que as organizações públicas assumam de fato a preocupação com a melhoria da qualidade de vida das pessoas e a diminuição das desigualdades sociais, comprovando que têm compromisso com a qualidade de seus serviços. (GERZSON; MÜLLER, 2009, p.64).

Juntamente com o trabalho jornalístico, a Superintendência de Comunicação Social desempenha funções de cerimonial, publicidade e propaganda.

\section{Democratização via internet}

$\mathrm{O}$ aumento na demanda por informações das atividades públicas cresceu juntamente com a quantidade de interessados, fato atrelado à proliferação da internet em todo o país. Segundo Nassif (2011), o total de usuários ativos de internet chegou a 43,2 milhões em março de 2011, o que significa uma evolução de 4,4\% na comparação com o mês anterior, segundo pesquisa do Instituto Brasileiro de Opinião Pública e Estatística (Ibope) divulgada no mês de março. Em relação aos 37,9 milhões de usuários ativos de março de 2010, o aumento foi de 13,9\%.

Em 2005, o site da Prefeitura Municipal de Castro registrou cerca de 25 mil acessos por mês. Em 2009 este número chegou a 65 mil e, em 2011, alcançou os 70 mil acessos. O número de acessos por mês já supera a quantidade de habitantes do município.

De acordo com Nassif (2011), o Plano Nacional de Banda Larga (PNBL) prevê um incremento ainda maior no universo dos usuários de internet do país. A meta do governo é massificar, até 2014. Para isso, o Ministério das Comunicações pretende definir, até o fim de junho deste ano (2011), um plano de metas para oferecer internet em larga escala por $\mathrm{R} \$$ 35, com o intuito de disponibilizar o acesso à internet em banda larga a $70 \%$ da população brasileira. Tal expansão é indicada em destaque:
A maior parte do crescimento do número de internautas nos últimos meses pode ser atribuída - segundo o instituto - ao aumento da presença de computador com internet nas residências. No período de um ano, o total de usuários ativos de internet no domicílio cresceu $20,7 \%$, ao passar de $29,1 \mathrm{mi}-$ lhões para 35,1 milhões. O Ibope considerou como usuário ativo pessoas com dois anos ou mais de idade que utilizaram pelo menos uma vez em março computador com internet. (NASSI, 2011, p.1).

Em Castro este investimento em comunicação acontece com o programa Castro Digital, que visa democratizar a internet no meio urbano e rural. A modernização da gestão pública já pode ser verificada através dos serviços e facilidades para o cidadão via online, que leva à comunidade uma nova perspectiva de cidadania. No âmbito da administração houve a integração entre todas as entidades diretas e indiretas, as estruturas tributária, financeira e administrativa, possibilitando acesso imediato às informações e serviços, e comunicação via Voip (voz sobre protocolo de internet). Para o cidadão, o acesso à internet já é livre e gratuito por sinal wireless em toda a cidade. Ao fazer um levantamento quantitativo dos acessos já realizados, pode ser citado:

- média de visitas mensais em 2005: 25 mil;

- média de visitas mensais em 2006: 45 mil.

- média de visitas mensais em 2009: 65 mil.

- média de visitas mensais em 2011: já passa de 70 mil.

A partir de 2011 está à disposição dos interessados não só de Castro, mas também de qualquer outro local, o Portal da Transparência da Prefeitura Municipal de Castro disponível na internet ${ }^{1}$. Esta ferramenta divulga para a população dados e contas públicas e cumpre a exigência da Lei Complementar Federal n ${ }^{\circ} 131 / 2009^{2}$ que estipulou a data de 27 de maio de 2011 para que os municípios com população entre 50 e 100 mil habitantes se adaptassem à exigência da lei.

\footnotetext{
${ }^{1}$ O Portal da Transparência da Prefeitura de Castro pode ser encontrado no site: http:/www.atende.net/transparencia/portal.php?cliente=2859

${ }^{2}$ Lei Complementar $\mathrm{N}^{\circ} 131$, de 27 de maio de 2009 pode ser acessada no site: http://www.planalto.gov.br/ccivil_03/leis/lcp/lcp131.htm
} 


\section{Considerações Finais}

O trabalho avaliou a importância da comunicação na gestão pública, analisando o caso da Prefeitura de Castro - Pr. Foram buscados os aspectos ligados aos limites éticos e profissionais da assessoria de comunicação de órgãos públicos frente às políticas públicas, planejamento estratégico e gestão operacional, quando se trata do controle das ações dos gestores. Foi dada atenção ao valor da comunicação para a prestação de contas junto à sociedade, mostrando onde foi empregado o dinheiro público e a problemática de tal ação em relação aos interesses políticos e ao valor ético, disponibilização nas informações de maneira transparente e útil, sem estar embutida de algum intuito eleitoreiro.

Com a maior acessibilidade às mídias comunicacionais, decorrente do crescente avanço tecnológico, a mudança de comportamento do cidadão frente à cobrança dos serviços prestados pelos governos e a responsabilização dos governantes por irregularidades, fica claramente comprovada a necessidade da existência de ferramentas que demonstrem a transparência das administrações públicas.

Esta mudança de comportamento, aliada às leis que exigem a transparência da gestão pública, motiva um crescente interesse do público pelas ações governamentais e maior responsabilidade da gestão ao informar à população o destino dos recursos públicos.

No exemplo da Prefeitura de Castro foi demonstrado que em diversos fatores existe a preocupação de manter o cidadão informado das ações de políticas públicas e de transparência. No entanto, para se consolidar tal estratégia de comunicação, é necessário que os gestores públicos, no caso do prefeito e dos secretários municipais, estejam preparados para atender e, principalmente, entender a sistemática da imprensa.

Além de preparar o primeiro escalão para se tornarem fonte de informação dos veículos de comunicação, cabe aos profissionais de assessoria de imprensa acompanhar as ações e diariamente disponibilizá-las a jornais, rádios, sites e emissoras de TV.

Os meios de comunicação próprios do município, criados pela Superintendência, cumprem um papel fundamental em uma demanda direcionada para públicos específicos que se interessam por uma ou outra área de atuação, mas que também serve para toda a sociedade.

O interesse público também foi discutido, considerando que este é o principal fator da existência de um intermediador entre a gestão e a população. Os assuntos devem ser de relevância para o coletivo e não para o governante.

Além de assuntos de interesse público, a gestão que deseja uma maior integração com a população nas decisões políticas supre de informação, mas também cria atrativos para uma maior adesão popular, na busca de levar a público a transparência na governança e a visibilidade nas políticas públicas desempenhadas no município.

A internet entra neste cenário como um ponto chave, pois evita que os usuários tenham que se deslocar até o paço municipal, já que disponibiliza os serviços online em seu portal, inclusive pela facilidade de acesso à internet com a oferta do sinal wireless gratuito para os munícipes. Todos estes fatores contribuem para que a quantidade de acessos seja diária, às vezes mais de uma vez ao dia, e que, com isso, o cidadão sempre "dê uma olhadinha" nas notícias relacionadas com as ações da gestão pública de sua cidade.

\section{Referências}

BRANDÃO, Elisabeth Pazito. Usos e significados do conceito comunicação pública. 2006. Disponível em: $<$ http://www.rp-bahia.com.br/biblioteca/intercom2006/ resumos/R1037-1.pdf $>$. Acesso em: 01 jul. 2011.

BUCCI, Maria Paula Dallari. Políticas públicas: reflexões Sobre o Conceito, Editora Saraiva, 2006.

CUNHA, Maria A. V. C. Meios eletrônicos e transparência: a interação do vereador brasileiro com o cidadão e o poder executivo. In: CONGRESO INTERNACIONAL DEL CLAD SOBRE LA REFORMA DEL ESTADO Y DE LA ADMINISTRACIÓN PÚBLICA, 10. Santiago, Chile, 18 - 21 Oct. 2005. Disponível em: <https://bvc.cgu.gov.br/ handle/123456789/3045>. Acesso em: 05 set. 2011.

DUARTE, Jorge. Comunicação pública. Disponível em: <http://www.jforni.jor.br/forni/files/ ComP\%C3\%BAblicaJDuartevf.pdf>. Acesso em: 03 jul. 2011.

FENAJ. Manual de assessoria de imprensa. 2007. Disponível em: $<$ http://www.fenaj.org.br/mobicom/manual de_assessoria_de_imprensa.pdf $>$. Acesso em: 18 mai. 2011. 
FERREIRA, Michelle Karen de Brunis. As novas configurações da gestão pública: comunicação, conhecimento e pessoas. Disponível em: $<$ http://www.faac. unesp.br/publicacoes/anais-comunicacao/textos/34.pdf $>$. Acesso em: 20 out. 2011.

GERZSON, Vera Regina Serezer; MÜLLER, Karla Maria. PROCAC/ Canoas: comunicação pública e relacionamento com o cidadão. Revista FAMECOS, Porto Alegre, n.38, abril 2009.

GOMES Filho, Adhemar Bento. O desafio de implementar uma gestão pública transparente. In: CONGRESO INTERNACIONAL DEL CLAD SOBRE LA REFORMA DEL ESTADO Y DE LA ADMINISTRACIÓN PÚBLICA, 10. Santiago, Chile, 18 - 21 Oct. 2005

GUEDES, Gilberto Gomes; MOREIRA, Manoel Henrique Tavares. O sucesso estratégico depende da comunicação. Universitas: Arquit. e Comun. Social, Brasília, v. 5 n. 1/2, p. 69-76, jan./dez. 2008. Disponível em: <http://www. publicacoesacademicas.uniceub.br/index.php/arqcom/ article/viewFile/658/709>. Acesso em: 15 set. 2011.

LOPES, Maria Immacolata Vassallo. La investigación en Comunicación: cuestiones epistemológicas, teóricas y metodológicas. Diálogos de la comunciación, Lima - peru, v. no. 56, p. 13-27, 1999. Disponível em: <http://www. yoemito.com/apoyo/MariaVassallo.pdf $>$. Acesso em: 23 set. 2012.

LOPES, Cristiano Aguiar Lopes. Caderno de finanças públicas, 2007, Disponível em: <http://www.esaf.fazenda. gov.br/esafsite/publicacoes-esaf/caderno-finanças/CFP8/ CFP_n8.pdf>. Acesso em: 29 mai. 2011.

MALMEGRIN, Maria Leonídia. Gestão operacional. Florianópolis: Departamento de Ciências da Administração / UFSC; [Brasília]: CAPES: UAB, 2010.

NASSIF, Luis. O crescimento da internet no Brasil. 2011. Disponível em: <http://www.advivo.com.br/blog/luisnassif/ o-crescimento-da-internet-no-brasil>. Acesso em: 22 out. 2011.

OLIVEIRA, M. J. C. Gestão pública, comunicação e cidadania: o caso da prefeitura municipal de Campinas. In: CONGRESSO BRASILEIRO DE CIÊNCIAS DA COMUNICAÇÃO, 26. Belo Horizonte. Anais... Belo Horizontes, 2003, p.1-13.

ROSA, Rosane. Um olhar sobre a cobertura jornalística de políticas públicas do jornal Zero Hora, 2010. Disponível em: <http://www.periodicos.ufsc.br/index.php/jorna-lismo/ article/view/15130/14458>. Acesso em: 04 abr. 2011.

ROLLO, Arthur. A propaganda eleitoral antecipada, 2011. Disponível em: <www.tre-sc.gov.br/site/fileadmin/arquivos/ ejesc/documentos/.../a.doc>. Acesso em: 22 out. de 2011.
RUIZ, Rodolpho Weishaupt. O desafio da comunicação em planejamento estratégico, Disponível em: <http://www. comtexto.com.br/2convicomteoriacomempreRodolphoRuiz. htm>. Acesso em: 22 de out. de 2011.

SANTOS, José Manuel. Ética da comunicação. Disponível em: http://www.bocc.ubi.pt/pag/santos-jose-manuel-eticacomunicacao.pdf. Acesso em: 14 set. de 2011.

Recebido em: 2 de agosto de 2012 Aceito em: 5 de outubro de 2012 